\title{
The prevalence and management of central post-stroke pain at a hospital in Zimbabwe
}

\author{
Caryn Tatenda Mhangara ${ }^{1}$, Vaneshveri Naidoo ${ }^{1}$, Mokgobadibe Veronica Ntsiea $^{1}$ \\ 1. Physiotherapy Department, Faculty of Health Sciences, University of the Witwatersrand, Johannesburg, South Africa
}

Correspondence: Veronica Ntsiea; Veronica.Ntsiea@wits.ac.za; Twitter@VNtsiea

\begin{abstract}
Background
Abstract

Central post-stroke pain (CPSP) is a poorly diagnosed chronic pain. It is under-treated and usually mismanaged.

Objective

To establish the prevalence of CPSP and its management in stroke clinics at a tertiary hospital.

Methods

This was a cross-sectional design with stroke patients and health professionals from the stroke clinic at the tertiary hospital in Zimbabwe. Results

Out of 166 stroke survivors, 8\% had CPSP. Younger age ( $<60$ years) was significantly associated with CPSP (P<0.003). Pain characteristics of CPSP were hyperaesthesia (10,71\%), electric shocks $(9,64 \%)$, temperature allodynia $(9,64 \%)$ and allodynia $(12$, $86 \%)$. Ten health professionals participated in the study: one (10\%) reported using Douleur Neuropathique 4 (to diagnose neuropathic pain) and two (20\%) reported using sensory tests. Four patients (44\%) were on paracetamol (acetaminophen) and on weak opiates such as codeine. None of the patients were on anticonvulsants or antidepressants. Two medical doctors (50\%) used weak opiates as second-line management. Five patients $(36 \%)$ reported receiving a combination of massage, stretching, general exercise and moist heat or cryotherapy.

Conclusion

The prevalence of CPSP in the study group is within international range. There is a need for appropriate management and use of tests and outcome measures for diagnosis of CPSP.
\end{abstract}

Key Words; Central post-stroke pain, chronic pain, Zimbabwe

\section{Introduction}

Central post-stroke pain (CPSP) is defined by the International Association for the Study of Pain (IASP) as 'pain initiated or caused by a primary lesion or dysfunction of the central nervous system" ${ }^{1}$ and occurs in the absence of other nociceptive, peripheral and psychogenic pain ${ }^{2}$. Aetiology of neuropathic pain is lesion in the central (brain and spinal cord) or peripheral nervous system ${ }^{1}$, whereas CPSP is only as a result of brain lesions and occurs in the body part that corresponds to the cerebrovascular lesion ${ }^{3}$. Allodynia, somatosensory deficits and dysaesthesia are more prominent in $\mathrm{CPSP}^{4,5}$. Klit et al. $^{3}$ also proposed that the supporting criteria for diagnosing CPSP also include pain descriptors, presence of allodynia to touch or temperature, especially cold, and the absence of inflammation, local tissue damage or pain due to movement. Essentially a diagnosis of CPSP is made by exclusion of other probable causes and this makes it difficult to diagnose.

The prevalence of CPSP varies between $1 \%$ and $12 \%$ in Europe and America ${ }^{6-8}$. When the CPSP criteria is used as proposed by Klit et alpartly owing to the difficulty in distinguishing this syndrome from other pain types that can occur after stroke (such as shoulder pain, painful spasticity, persistent headache, and other musculoskeletal pain conditions. ${ }^{3}$, prevalence has been found to be approximately 4-11\%. There are several factors associated with CPSP including younger age $e^{9}$ diabetes and female $\operatorname{sex}^{5}$. Current smoking and previous history of depression as well as the baseline severity of the stroke are also associated with
$\mathrm{CPSP}^{10}$. The literature on factors associated with CPSP seems to be inconclusive on factors such as age, sex, side of stroke and laterality and thus, after literature critique, the authors only focused on factors that were identified in studies that focused primarily on CPSP. Central post-stroke pain may occur 1-2 months post-stroke ${ }^{11}$ but has a higher incidence in the subacute and chronic stages of stroke than acute stages $^{12}$.

Patients describe the pain as burning, freezing, cutting or squeezing ${ }^{13}$. Post-stroke pain leads to inhibition of movement, depression and inability to perform activities of daily living ${ }^{14}$. It also affects return to employment as well as work performance ${ }^{15}$. Management of CPSP is difficult as it does not respond well to analgesics and non-pharmacologic treatments. However, therapeutic effects are found with antidepressants and anti-epileptics such as gabapentin, lamotrigine and pregabalin ${ }^{16}$.

Positive effects on reducing CPSP have been found with antidepressants and anti-epileptics including exercise ${ }^{17,18}$, transcutaneous electrical nerve stimulation ${ }^{19}$, cognitive behavioural therapy $(\mathrm{CBT})^{14,20}$, therapeutic neuroscience education (TNE) $)^{21,22}$ and graded motor imagery ${ }^{23}$. There is poor evidence for the use of trans-cranial direct stimulation, trans-cranial magnetic stimulation and caloric vestibular stimulation $^{24-26}$. There is limited information about CPSP and its prevalence, as well as its medical and therapeutic management in African populations. A search of the literature yielded one published research in Nigeria on an 
African population, with a CPSP prevalence of $5 \% 0^{27}$. Thus the aim of this study is to establish the prevalence of CPSP and its management in stroke clinics at a hospital where one of the researchers (CTM) is based which will add to the literature for African populations.

\section{Methods}

This was a quantitative, cross-sectional, descriptive study. The study was conducted at an academic hospital in Harare, Zimbabwe. The hospital has 1800 beds and is a centre for training of medical professions such as medicine, rehabilitation and nursing. There were two physicians in charge of the outpatient medical clinic, and five medical officers (junior medical doctors), who rotate to other specialties every 4 months. The rehabilitation department had four physiotherapists and two occupational therapists. The hospital has a specialised stroke unit for the management of in-patients during the acute stroke period. After they are discharged from hospital these patients are referred for continuation of care at the medical and rehabilitation outpatient stroke clinics at the same hospital. The stroke survivors and health professionals were recruited from these clinics.

Stroke survivors were included in the study according to the following criteria: men and women above the age of 18 years whose first ever stroke had occurred between 1 month and 5 years previously; who attended a stroke clinic at the hospital; and had confirmation of a stroke using MRI and CT scan of clinical diagnosis. The exclusion criteria were as follows: previous history of neuropathy or other chronic pain not related to stroke; several strokes previously as per medical records or patient's report (to exclude possible nonneuropathic causes of pain from previous stroke related impairments); aphasia; or dysarthria.

The sample size for stroke survivors was determined using the following: estimate of the expected proportion $(p)=12 \% 0^{6,7}$; desired level of absolute precision $(d)=0.05$; and estimated design effect (DEFF) $=1$ (standing for one cluster at the hospital) with a sample formula of $n=1.96^{2} \times \mathrm{p}(1$ - p) $/ 0.05^{2}=\left[1.96^{2} \times 0.12(1-0.12)\right] / 0.05^{2}$. Therefore a minimum sample size of 163 stroke survivors was needed for this study; 166 patients participated. All 13 health professionals were invited and 10 participated in the study.

\section{Instrumentation and outcome measures}

The Leeds Assessment of Neuropathic Symptoms and Signs (LANSS) was used to detect presence of pain and to positively identify the neuropathic nature of the pain in participants who complained of pain post-stroke. A total score above 12 shows likeliness of a neuropathic mechanism contributing to the pain ${ }^{28}$. Diagnosis of CPSP was through the use of screening questions to exclude those with nonCPSP type pain (nociceptive, peripheral and psychogenic) and to check that the affected body part corresponds to the cerebrovascular lesion.

Patient-related information was captured using a selfdesigned questionnaire and patients' treatment notebooks and included the following: demographic information, drug and rehabilitation interventions, clinical information, comorbidities and pain. The following were captured through the health professionals' questionnaire: demographic information; level of experience; knowledge of CPSP; and treatment strategies used. The questionnaire did not require the medical doctors to specify drugs and thus only drug categories were captured. The questionnaires were developed with the aid of the literature and experts involved in the management of stroke survivors. The panel of experts included two physiotherapists (one with experience in stroke rehabilitation and the other in pain management), one occupational therapist with experience in stroke rehabilitation and one physician.

\section{Procedure}

The data collection period was from January 2017 to May 2017. Stroke survivors were approached consecutively in the hospital medical and rehabilitation stroke clinics and invited to participate in the study. For stroke survivors who answered in the affirmative to having pain that started after the stroke, a sensory examination was conducted and scored according to the LANSS.

The researcher also tested for soft/deep touch and hot/cold sensation. Sensation testing was done on the painful area as well as the corresponding opposite limb at the same site (used as the control/normal). A cotton swab was used to test soft touch and the blunt end of a pen for deep touch. Hot sensation was tested using a test tube with warm water at 36 $40^{\circ} \mathrm{C}$ and cold sensation using water at $5-10^{\circ} \mathrm{C}$. The second part of the LANSS was administered on the participants who complained of pain on their hemiplegic side. The participants were blindfolded to keep their eyes closed during this examination. The researcher noted the presence of allodynia by lightly stroking with the cotton wool over the painful and the non-painful areas. The researcher also noted any altered pin-prick sensation/dysaesthesia in both painful and non-painful areas by pressing gently with a toothpick on the skin.

For the health professionals, questionnaires were hand delivered. Confidentiality was ensured by providing selfsealing opaque envelopes for the completed questionnaires and a sealed box at the work station for dropping off completed questionnaires. A reminder by short messaging system or WhatsApp was sent 2 days after delivery of the questionnaire. The sealed boxes were then collected 7 days after delivery of the questionnaires. Ethical clearance was obtained from the Joint Research and Ethics Committee (JREC/206/16), the Medical Research Committee (MRCZ/B/1122) in Zimbabwe and Human Research Ethics Committee of the University of the Witwatersrand (M160619).

\section{Data analysis}

Data was captured on an Excel spreadsheet and exported to Epi-Info 7 for analysis. Descriptive statistics were presented as frequencies and percentages. Odds ratios were used to measure association between bio-socio-economic factors and CPSP.

\section{Results}

The number of stroke patients in the study was 166 with a mean age of $60.9 \pm 15.6$ years that ranged from 24 to 97 years. The social demographics of the stroke patients are presented in Table 1. Over two-thirds of the participants were women (70\%) and living on less than $\$ 50$ (USD) average monthly 
income $(67 \%)$. Three-quarters $(76 \%)$ were unemployed and $34 \%$ were from rural areas. Eighty-four percent of the study population sustained an ischaemic stroke and the rest $(16 \%)$ had haemorrhagic stroke, and $58 \%$ had stroke in the left hemisphere. Table 2 shows the results of the LANSS scores for all stroke patients. Fourteen patients $(8 \%)$ had a LANSS score $>12$ (positive for CPSP). The rest of the study participants had pain but it was not considered CPSP.

Table 1. Social demographics of stroke patients ( $n=166)$.

\begin{tabular}{|c|c|c|}
\hline Characteristic & Variable & $n(\%)$ \\
\hline \multirow[t]{2}{*}{ Sex } & Male & $50(30)$ \\
\hline & Female & $116(70)$ \\
\hline \multirow[t]{4}{*}{ Marital status } & Married & $99(60)$ \\
\hline & Single & $15(9)$ \\
\hline & Divorced & $8(5)$ \\
\hline & Widowed & $44(27)$ \\
\hline \multirow{3}{*}{$\begin{array}{l}\text { Area of } \\
\text { residence }\end{array}$} & Rural & $57(34)$ \\
\hline & Urban high density & $79(48)$ \\
\hline & $\begin{array}{l}\text { Urban medium/low } \\
\text { density }\end{array}$ & $30(18)$ \\
\hline \multirow{3}{*}{$\begin{array}{l}\text { Employment } \\
\text { status at time } \\
\text { of stroke incident }\end{array}$} & Formal & $22(13)$ \\
\hline & Informal & $18(11)$ \\
\hline & Unemployed & $126(76)$ \\
\hline \multirow{4}{*}{$\begin{array}{l}\text { Average monthly } \\
\text { income in \$ (USD) }\end{array}$} & $<50$ & $111(67)$ \\
\hline & $51-100$ & $24(15)$ \\
\hline & $101-300$ & $26(16)$ \\
\hline & $>300$ & $5(3)$ \\
\hline \multirow{3}{*}{$\begin{array}{l}\text { Stroke } \\
\text { duration }\end{array}$} & $1-3$ months & $20(12)$ \\
\hline & $3-6$ months & $82(49)$ \\
\hline & $>6$ months & $64(39)$ \\
\hline
\end{tabular}

Table 2. Leeds Assessment of Neuropathic Symptoms and Signs (LANSS) scores for stroke patients ( $n=166)$.

\begin{tabular}{|l|l|l|}
\hline Total score & Frequency & $\%$ \\
\hline 0 & 107 & 65 \\
\hline $1-11$ & 45 & 27 \\
\hline $12-24^{\mathrm{a}}$ & 14 & 8 \\
\hline Total & 166 & 100 \\
\hline
\end{tabular}

\section{Patients with central post-stroke pain}

The median age of patients with CPSP was 58 years. Ischaemic stroke accounted for 13 of 14 patients (93\%) and $71 \%$ had left stroke. Table 3 shows the descriptions of pain by the CPSP patients using the LANSS tool. Most participants had pain that never stopped (43\%), and reported pain linked with hyperaesthesia $(71 \%)$. Allodynia was present in nearly all participants (86\%). Results of associations between demographic/clinical factors and CPSP are shown in Table 4. Those who were below 60 years of age were five times more likely to develop CPSP than those aged above 60 $(P<0.0035)$.
Table 3. Pain descriptors of central post-stroke pain $(n=14)$.

\begin{tabular}{|c|c|c|}
\hline Variable & Characteristics & n (\%) \\
\hline \multirow[t]{3}{*}{ Pain frequency } & Not often & $5(36)$ \\
\hline & Often & $3(21)$ \\
\hline & Never stops & $6(43)$ \\
\hline \multirow[t]{2}{*}{ Hyperaesthesia } & Yes & $10(71)$ \\
\hline & No & $4(29)$ \\
\hline \multirow[t]{2}{*}{ Electric shocks } & Yes & $9(64)$ \\
\hline & No & $5(36)$ \\
\hline \multirow{2}{*}{$\begin{array}{l}\text { Pain with } \\
\text { temperature } \\
\text { changes }\end{array}$} & Yes & $9(64)$ \\
\hline & No & $5(36)$ \\
\hline \multirow[t]{2}{*}{ Allodynia } & Yes & $12(86)$ \\
\hline & No & $2(14)$ \\
\hline \multirow[t]{2}{*}{ Hyperalgesia } & Yes & $11(79)$ \\
\hline & No & $3(21)$ \\
\hline
\end{tabular}

Table 4. Demographic and clinical factors associated with central post-stroke pain $(n=14)$.

\begin{tabular}{|l|l|l|l|l|l|}
\hline Variable & Characteristic & CPSP & Non-CPSP & $\begin{array}{l}\text { Odds ratio } \\
\left(95 \% \text { confidence }^{\text {interval }}\right)^{\mathrm{a}}\end{array}$ & P-value \\
\hline Age & $<60$ years $^{\mathrm{b}}$ & 3 & 18 & $5.47(1.47-20.42)$ & 0.0035 \\
\hline Sex & $>60$ years & 11 & 134 & & \\
\hline & Male & 6 & 44 & $1.84(0.60-5.61)$ & 0.149 \\
\hline $\begin{array}{l}\text { Stroke } \\
\text { type }\end{array}$ & Ischaemic & 13 & 127 & $0.30(0.05-3.12)$ & 0.2 \\
\hline & Haemorrhagic & 1 & 25 & & \\
\hline Diabetes & Yes & 8 & 108 & $1.41(0.29-6.86)$ & 0.33 \\
\hline & No & 12 & 135 & & \\
\hline HIV & Yes & 1 & 22 & $0.45(0.06-3.65)$ & 0.25 \\
\hline Nlcohol & Yes & 2 & 31 & $0.65(0.14-3.06)$ & 0.32 \\
\hline & No & 12 & 121 & & \\
\hline
\end{tabular}

\section{Management of central post-stroke pain by bealth professionals}

Ten medical professionals (two occupational therapists, four physiotherapists, three medical officers and one physician) responded to the questionnaire. Eight of the health professionals were in the 20-30 age group and four had less than 1 year of experience practising their profession, with the rest having 1-3 years of experience (two health professionals), 4-5 years (two) or greater than 5 years (two).

The patient treatment notebooks did not indicate a specific diagnosis of CPSP. 
Table 5. Treatment received by patients with central post-stroke pain $(n=14)$.

\begin{tabular}{|l|l|l|}
\hline Variable & Characteristic & $n(\%)$ \\
\hline \multirow{4}{*}{ Drugs } & Yes & $9(64)$ \\
\cline { 2 - 3 } & No & $5(36)$ \\
\hline \multirow{5}{*}{ Other } & NSAIDs & $1(11)$ \\
\cline { 2 - 3 } & Weak opioids & $4(44)$ \\
\cline { 2 - 3 } & Paracetamol & $4(44)$ \\
\hline & Massage & $3(21)$ \\
\cline { 2 - 3 } & Stretching & $1(7)$ \\
\cline { 2 - 3 } & Heat/cold & $1(7)$ \\
\cline { 2 - 3 } & $\begin{array}{l}\text { Combination } \\
\text { ( m a s s a g e } \\
\text { stretching, } \\
\text { heat/cold) }\end{array}$ & $5(36)$ \\
\cline { 2 - 3 } & None & $2(14)$ \\
\cline { 2 - 3 } & $\begin{array}{l}\text { Other (prayer, } \\
\text { meditation) }\end{array}$ & $2(14)$ \\
\hline
\end{tabular}

Table 6. Management of central post-stroke pain by health professionals $(\mathbf{n}=10)$.

\begin{tabular}{|c|c|c|}
\hline Variable & Characteristic & $n(\%)$ \\
\hline \multirow[t]{3}{*}{$\begin{array}{l}\text { Management } \\
\text { approacha }^{\text {a }}\end{array}$} & Multidisciplinary & $3(30)$ \\
\hline & Interdisciplinary & $5(50)$ \\
\hline & Monodisciplinary & $2(20)$ \\
\hline \multirow[t]{2}{*}{ Outcome measures } & Yes & $1(10)$ \\
\hline & No & $9(90)$ \\
\hline \multicolumn{3}{|l|}{$\begin{array}{l}\text { Management by } \\
\text { medical doctors } \\
(n=4)\end{array}$} \\
\hline \multirow{4}{*}{ First-line } & Analgesics & $2(50)$ \\
\hline & Anti-epileptics & $2(50)$ \\
\hline & Antidepressants & $2(50)$ \\
\hline & Don't know & $1(25)$ \\
\hline \multirow{5}{*}{ Second-line } & Anti-epileptics & $1(25)$ \\
\hline & Antidepressants & $1(25)$ \\
\hline & Opiates & $2(50)$ \\
\hline & $\begin{array}{c}\text { Refer to physiother- } \\
\text { apy }\end{array}$ & $1(25)$ \\
\hline & Refer to psychiatry & $1(25)$ \\
\hline \multicolumn{3}{|l|}{$\begin{array}{l}\text { Management } \\
\text { by therapists }(n=6)\end{array}$} \\
\hline & Interferential & $2(33)$ \\
\hline & Ultrasound & $2(33)$ \\
\hline & Hydrotherapy & $1(17)$ \\
\hline & TNE & $2(33)$ \\
\hline & CBT & $2(33)$ \\
\hline & Moist heat & $2(33)$ \\
\hline & Exercise & $6(100)$ \\
\hline & Heat rub & $3(50)$ \\
\hline
\end{tabular}

Table 5 shows the medications and therapy used by patients with CPSP. Some $(36 \%)$ of the CPSP patients were not on any medication. Paracetamol (acetaminophen) and weak opioids such as codeine accounted for approximately $44 \%$ of those receiving medication. The management of CPSP as reported by health professionals is presented in Table 6 . Half of the health professionals reported using an interdisciplinary approach (referral to other disciplines, active engagement and follow up on what they had done) for the management of CPSP. One medical doctor did not know what first-line drug management to use for CPSP. Also, only one medical doctor referred patients for physiotherapy, occupational therapy or psychiatry. Fifty percent of the therapists used heat rub for treatment, whilst 33\% used moist heat. All the therapists included exercise as part of their treatment regimen.

\section{Discussion}

\section{Prevalence of central post-stroke pain}

Fourteen of the patients had CPSP and this translated to 8\% of this sample. Considering that outpatient stroke burden for 2015 at the hospital where this study was conducted was 1791 patients, approximately $143(8 \%)$ of these patients would have CPSP. This meant that CPSP was not a rare condition. None of the 14 patients with CPSP had a diagnosis of CPSP prior to this study. This meant that all these patients were unlikely to be receiving management in line with their condition of CPSP. It would mean that the 143 annual CPSP cases at the hospital would also not have received management in line with CPSP. The prevalence rate of $8 \%$ in this study was within the range of $4-11 \%$ as found in the literature ${ }^{3,10,29}$. This prevalence rate was low compared with other studies which had follow-up of patients at predetermined intervals ${ }^{9,12}$. If follow-up testing sessions had been conducted the prevalence may actually have been higher. The timing of recruitment into the study was designed to coincide with the prime development of CPSP ${ }^{12}$.

There was a high incidence of allodynia 12 (86\%) in the CPSP patients. This is similar to the study by Klit et al. ${ }^{29}$ who found 23 of the patients $(66 \%)$ had allodynia and dysaesthesia. This is also similar to the study by Hansen et al. which found 29 of the patients with CPSP $(14 \%)$ to have provoked allodynia, whereas it was spontaneous in $66 \%$ of patients ${ }^{5}$. Allodynia has been found to be a hallmark symptom of CPSP, and the results from this study further confirm this. Temperaturerelated pain and electric shocks were reported in 9 of the patients (64\%) with CPSP. This was similar to the $62 \%$ reported by Greenspan et al. ${ }^{30}$ and the $64 \%$ reported by Klit et al. ${ }^{29}$ Allodynia and temperature-related pain/electric shocks interfere with activities of daily living and this may lead to patients isolating themselves from physical, social or economic activities, and further on may cause disability and handicap. Pain frequency was described as 'never stopping' by six patients with CPSP. This meant their pain would affect a substantial part of their day and possibly inhibit them from participating in activities of daily living and other economic activities.

\section{Bio-socio-economic factors associated with central post-stroke pain}

Age was the only factor that was found to have an association with CPSP in this study. Younger participants (60 years and below) were more likely to develop CPSP $(P<0.003)$. The ages most affected by CPSP were still economically 
productive, meaning that they would lose many work hours due to the pain and they would also not fulfil their social roles adequately. In a study by Klit et al. ${ }^{29}$, younger age of 60 and below was also found to have an association with development of CPSP. Hansen et al. ${ }^{5}$ also found a significant association between age and CPSP, with a mean age of $60.4 \pm 6.2$ years. It has not yet been established why younger age is associated with CPSP, and it was beyond the scope of this study to do so. Further studies into this area are required.

Patients below the age of 65 at government hospitals such as the one where this research was conducted are required to pay for each service needed. The fees for physician, occupational therapy, physiotherapy and drug/medication are all paid separately. The patients with CPSP had a median age of 58 years and were ineligible for free treatment. The majority of the patients with CPSP were also living on less than $\$ 50$ per month. This meant that they would not be able to pay for the medical services. It is possible that inability to pay would seriously compromise their health and quality of life. All 14 patients with CPSP were also in the age group of possible economic productivity. Having a debilitating chronic pain syndrome such as CPSP would affect their ability to provide for themselves and their families financially.

\section{Management of central post-stroke pain by health professionals}

The scope of this study was not to measure the knowledge of the medical practitioners of CPSP; however, the medical practitioner participants could identify that CPSP occurred after a stroke. Nevertheless, this did not translate to them specifically identifying CPSP in the population of stroke patients attending the outpatient clinics. Diagnosis of CPSP in this study was done through the use of screening questions to exclude those with non-CPSP type pain and the LANSS questionnaire to positively identify the neuropathic nature of the CPSP. The poor identification of CPSP meant that planning for medication availability and rehabilitative treatment time would be negatively affected. Patients with CPSP would constantly require medications according to the evidence-based drug management, and therefore drugs to manage the CPSP would have to be stocked in accordance to this prevalence. They would also require more rehabilitative therapy treatment time, as the pain frequently disrupts therapy sessions.

Evidence-based practice proposes the use of antidepressants and anticonvulsants in the drug management of $\mathrm{CPSP}^{8,26}$. Almost two-thirds of participants with CPSP $(9,64 \%)$ were on medication in this study. Paracetamol (44\%), weak opiates such as codeine (44\%) and non-steroidal anti-inflammatory drugs $(11 \%)$ were used. None of these types of medication used to treat CPSP were of an evidence-based standard. The cost of antidepressants and anticonvulsants may have contributed to the patients not taking any of these drugs as most lived on less than $\$ 50$ per month and had to pay for their medication. Paracetamol was the drug most used. It does not need prescription by a medical doctor and is affordable, making it easily accessible to most patients. This may have accounted for its high usage. The drug treatment pattern was similar to that of Harno et al. ${ }^{9}$ who also had most of their patients on analgesics such as paracetamol $(24,85 \%)$ and weak opioids (10,35\%). Within the Essential Drug List in Zimbabwe (EDLIZ) ${ }^{31}$, there is no mention of treatment of stroke pain and therefore no guidelines as to which drug treatment may be useful for stroke pain specifically. However, the EDLIZ has guidelines on treatment of peripheral sensory symptoms and recommends the use of amitriptyline in doses from $25 \mathrm{mg}$ to $75 \mathrm{mg}$ once daily, with the lower dose most recommended. It further recommends that if amitriptyline is ineffective or causes intolerable adverse effects, then the use of carbamazepine or opiates such as codeine or morphine sulfate would be warranted.

Two of the medical doctors reported they would prescribe antidepressants and anticonvulsants. These may not have been the doctors who saw the 14 participants with CPSP who did not have these medications because the doctors rotate regularly from the physician clinics except for the consultant physicians themselves. However, the consultant physicians only treat patients who are referred by the junior doctors. The junior doctors also had limited experience in treating stroke patients as most had less than 5 years experience postqualification. Thus they would likely know the signs and symptoms of CPSP but would not have had much practical experience in treating such a condition and would possibly miss a lot of information. Most of the health professional participants were not using any outcome measures to test for CPSP, nor did they use sensation tests or other neurological tests. All participants with CPSP were missed on diagnosis and this resulted in them being treated in a generic manner for chronic pain and not specific to a neuropathic pain such as CPSP. Use of outcome measures and sensation testing could be time-consuming and perhaps this accounted for the low uptake because the outpatient stroke clinics are usually busy, oversubscribed and with a low staff complement. Having a CPSP check-list or an algorithm for use when conducting the stroke clinics may assist in picking out patients who have $\mathrm{CPSP}^{32}$

Most participants with CPSP indicated that they received one or more therapy type treatments including exercise. This study did not investigate in depth the type, frequency or grading of exercise used by patients with CPSP, therefore it is not possible to determine whether the exercises used were beneficial or detrimental to the CPSP condition. Only a third of therapists used TNE and CBT. The local university curriculum may not have included formal teaching of TNE and CBT to both occupational therapists and physiotherapists, despite it being commonly used worldwide by various medical professionals ${ }^{14,33}$. A curriculum audit at the local university may be required to establish whether the CBT and TNE components are taught and the effectiveness and applicability of such training.

Three patients with CPSP $(21 \%)$ reported being massaged for the pain whilst five $(35 \%)$ received a combination of massage, stretch and hot/cold treatments. Although efficacy of treatment was beyond the scope of this study, these treatment modalities may make symptoms such as allodynia worse ${ }^{34,35}$. The efficacy of these treatments for other CPSP symptoms may still require further research in this setting.

\section{Conclusion}

The prevalence of CPSP is in line with other studies from both developed and developing countries. The only biosocio-economic factor associated with CPSP in this study is younger age. There is need for appropriate management and 
use of tests and outcome measures for diagnosis of CPSP. Continued education courses on management of patients with CPSP is required to improve evidence-based practice as some of the service limitations can be attributed to lack of knowledge/experience rather than shortage of resources.

\section{Limitations}

The participants were all from a clinical setting and within the sub-acute stage of stroke (up to 3 months), with very few at the chronic stage $(>6 \text { months })^{35}$. Sampling patients at the community level may increase the number of chronic stage participants. The number of participants with CPSP was low compared with those without CPSP and this affected the power of between-group comparisons. Confirmation of CPSP was based on exclusion of possible nociceptive, peripheral and psychogenic causes and on the link between area of pain and cerebrovascular lesion and thus may have included patients with complex regional pain syndrome of central origin if patients had trauma that was not reported. Given the high female ratio, and the lower social class, these results are not generalisable to stroke survivors outside the study setting.

\section{Recommendations}

Train health professionals in stroke clinics in CPSP assessment and treatment protocols; devise a checklist and treatment algorithm for post-stroke pain in general and CPSP in particular; raise awareness of the referral process and facilitation of the CPSP management interdisciplinary approach through seminars and team-building exercises; make drugs for CPSP more accessible to patients.

\section{Competing interests}

None to declare

\section{Author's' contributions}

Project leader: MCT.

Conceptualisation and design of the study: CTM, VN, MVN

\section{Data collection: CTM}

Data analysis and interpretation, writing and editing the manuscript: CTM, VN, MVN

\section{Acknowledgements}

The authors would like to thank Dr Mutsa Mhangara, Mr Steveson Dube, Mrs Rumbidzai Muzarurwi and the hospital outpatients team for support with data collection. We would also like to thank all the individual stroke patients and their families who agreed to take part in this research to further knowledge in the area of stroke pain.

\section{Funding}

None.

\section{References}

1. Merskey H, Bogduk N. Classification of chronic pain, IASP Task Force on Taxonomy [Internet]. Washington: IASP Press; 1994. [Cited 2018 Sep 10]. Available from: https://s3.amazonaws.com/rdcmsiasp/files/production/public/Content/ContentFolders/Publications2/ FreeBooks/Classification-of-Chronic-Pain.pdf.
2. Şahin-Onat Ş, Ünsal-Delialioğlu S, Kulaklı F, Özel S. The effects of central post-stroke pain on quality of life and depression in patients with stroke. J Phys Ther Sci. 2016;28(1):96-101. doi: 10.1589/jpts.28.96.

3. Klit H, Finnerup NB, Jensen TS. Central post-stroke pain: clinical characteristics, pathophysiology, and management. Lancet Neurol. 2009;8(9):857-68. doi: 10.1016/S1474-4422(09)70176-0.

4. Landerholm ÅH, Hansson PT. Mechanisms of dynamic mechanical allodynia and dysesthesia in patients with peripheral and central neuropathic pain. Eur J Pain. 2011;15(5):498-503. doi: 10.1016/j. ejpain.2010.10.003.

5. Hansen AP, Marcussen NS, Klit H, Andersen G, Finnerup NB, Jensen TS. Pain following stroke: a prospective study. Eur J Pain. 2012;16(8):1128-36. doi: 10.1002/j.1532-2149.2012.00123.x.

6. Sackley C, Brittle N, Patel S, Ellins J, Scott M, Wright C, et al. The prevalence of joint contractures, pressure sores, painful shoulder, other pain, falls, and depression in the year after a severely disabling stroke. Stroke. 2008;39(12):3329-34. doi: 10.1161/STROKEAHA.108.518563.

7. Lundström E, Smits A, Terént A, Borg J. Risk factors for strokerelated pain 1 year after first-ever stroke. Eur J Neurol. 2009;16(2):18893. doi: $10.1111 / \mathrm{j} .1468-1331.2008 .02378 . x$.

8. Klit H, Finnerup NB, Jensen TS. Diagnosis, prevalence, characteristics, and treatment of central poststroke pain. PAIN: Clinical Updates, IASP [Internet]. 2015 [cited 2018 Sep 10];23:1-7. Available from: https://s3.amazonaws.com/rdcms-iasp/files/production/public/ Content/ContentFolders/Publications2/PainClinicalUpdates/Archives/ pcu_vol23_no3_april2015_1429888393942_1.pdf.

9. Harno H, Haapaniemi E, Putaala J, Haanpaa M, Makela JP, Kalso E, et al. Central poststroke pain in young ischemic stroke survivors in the Helsinki Young Stroke Registry. Neurology. 2014;83(13):1147-54. doi: 10.1212/WNL.0000000000000818.

10. O’Donnell MJ, Diener HC, Sacco RL, Panju AA, Vinisko R, Yusuf S. Chronic pain syndromes after ischemic stroke: PRoFESS trial. Stroke. 2013;44(5):1238-43. doi: 10.1161/STROKEAHA.111.671008.

11. Kumar B, Kalita J, Kumar G, Misra UK. Central poststroke pain: a review of pathophysiology and treatment. Anesth Analg. 2009;108(5):1645-57. doi: 10.1213/ane.0b013e31819d644c.

12. Paolucci S, Iosa M, Toni D, Barbanti P, Bovi P, Cavallini A, et al. Prevalence and time course of post-stroke pain: a multicenter prospective hospital-based study. Pain Med. 2016;17(5):924-30. doi: 10.1093/pm/pnv019.

13. Henry JL, Lalloo C, Yashpal K. Central poststroke pain: an abstruse outcome. Pain Res Manag. 2008;13(1):41-9. doi: 10.1155/2008/754260.

14. Harrison RA, Field TS. Post stroke pain: identification, assessment, and therapy. Cerebrovasc Dis. 2015;39(3):190-201. doi: $10.1159 / 000375397$.

15. KuptniratsaikulV, KovindhaA, Suethanapornkul S, Manimmanakorn $\mathrm{N}$, Archongka Y. Complications during the rehabilitation period in Thai patients with stroke: a multicenter prospective study. Am J Phys Med Rehabil. 2009;88(2):92-9. doi: 10.1097/phm.0b013e3181909d5f.

16. Hoang CL, Salle JY, Mandigout S, Hamonet J, Macian-Montoro F, Daviet JC. Physical factors associated with fatigue after stroke: an exploratory study. Top Stroke Rehabil. 2012;19(5):369-76. doi: 10.1310/tsr1905-369.

17. Daenen L, Varkey E, Kellmann M, Nijs J. Exercise, not to exercise, or how to exercise in patients with chronic pain? Applying science to practice. Clin J Pain. 2015;31(2):108-14. doi: 10.1097/ AJP.0000000000000099.

18. Hodges PW, Smeets RJ. Interaction between pain, movement, and physical activity: short-term benefits, long-term consequences, and targets for treatment. Clin J Pain. 2015;31(2):97-107. doi: 10.1097/ AJP.0000000000000098.

19. Caglar NS, Akin T, Aytekin E, Komut EA, Ustabasioglu F, Okur 
$\mathrm{S}$, et al. Pain syndromes in hemiplegic patients and their effects on rehabilitation results. J Phys Ther Sci. 2016;28(3):731-7. doi: 10.1589/ jpts.28.73.

20. Archer KR, Motzny N, Abraham CM, Yaffe D, Seebach CL, Devin $\mathrm{CJ}$, et al. Cognitive-behavioral-based physical therapy to improve surgical spine outcomes: a case series. Phys Ther. 2013;93(8):1130-9. doi: $10.2522 /$ ptj.20120426.

21. Louw A, Zimney K, Puentedura EJ, Diener I. The efficacy of pain neuroscience education on musculoskeletal pain: a systematic review of the literature. Physiother Theory Pract. 2016;32(5):332-55. doi: 10.1080/09593985.2016.1194646.

22. Zhu Y, Su B, Li N, Jin H. Pain management of hemiplegic shoulder pain post stroke in patients from Nanjing, China. Neural Regen Res. 2013;8(25):2389-98. doi: 10.3969/j.issn.1673-5374.2013.25.010.

23. Bowering KJ, O'Connell NE, Tabor A, Catley MJ, Leake HB, Moseley GL, et al. The effects of graded motor imagery and its components on chronic pain: a systematic review and meta-analysis. J Pain. 2013;14(1):3-13. doi: 10.1016/j.jpain.2012.09.007.

24. Chen CC, Chuang YF, Huang AC, Chen CK, Chang YJ. The antalgic effects of non-invasive physical modalities on central poststroke pain: a systematic review. J Phys Ther Sci. 2016;28(4):1368-73. doi: $10.1589 /$ jpts.28.1368.

25. Mulla SM, Wang L, Khokhar R, Izhar Z, Agarwal A, Couban $\mathrm{R}$, et al. Management of central poststroke pain: systematic review of randomized controlled trials. Stroke. 2015;46(10):2853-60. doi: 10.1161/STROKEAHA.115.010259.

26. Kim JS. Pharmacological management of central post-stroke pain: a practical guide. CNS Drugs. 2014;28(9):787-97. doi: 10.1007/s40263014-0194-y.

27. Bashir AH, Abdullahi A, Abba MA, Mukhtar NB. Central poststroke pain: its profile among stroke survivors in Kano, Nigeria. Behav Neurol. 2017;2017. doi: 10.1155/2017/9318597. Article ID: 9318597.
28. Bennett M. The LANSS Pain Scale: the Leeds Assessment of Neuropathic Symptoms and Signs. Pain. 2001;92(1-2):147-57. doi: 10.1016/s0304-3959(00)00482-6.

29. Klit H, Finnerup NB, Andersen G, Jensen TS. Central poststroke pain: a population-based study. Pain. 2011;152(4):818-24. doi: 10.1016/j.pain.2010.12.030.

30. Greenspan JD, Ohara S, Sarlani E, Lenz FA. Allodynia in patients with post-stroke central pain (CPSP) studied by statistical quantitative sensory testing within individuals. Pain. 2004;109(3):357-66. doi: 10.1016/j.pain.2004.02.002.

31. Ministry of Health and Child Welfare. EDLIZ 2011: 6th essential medicines list and standard treatment guidelines for Zimbabwe. 6th ed. Harare: Ministry of Health and Child Welfare; 2011 [cited 2020 Apr 15]. Available from: https://zdhr.uz.ac. zw/xmlui/bitstream/handle/123456789/617/EDLIZ\%202011. pdf? sequence $=1 \&$ is Allowed $=y$.

32. Hebert D, Lindsay MP, McIntyre A, Kirton A, Rumney PG, Bagg S, et al. Canadian stroke best practice recommendations: stroke rehabilitation practice guidelines, update 2015. Int J Stroke. 2016;11(4):459-84. doi: 10.1177/17474993016643553.

33. Seal K, Becker W, Tighe J, Li Y, Rife T. Managing chronic pain in primary care: it really does take a village. J Gen Intern Med. 2017;32(8):931-4. doi: 10.1007/s11606-017-4047-5.

34. de Jong LD, Dijkstra PU, Gerritsen J, Geurts AC, Postema K. Combined arm stretch positioning and neuromuscular electrical stimulation during rehabilitation does not improve range of motion, shoulder pain or function in patients after stroke: a randomised trial. J Physiother. 2013;59(4):245-54. doi: 10.1016/S1836-9553(13)70201-7.

35. Lewis RP, Kriukelyte I. Complex neuropathic pain states. Anaesth. Intensive Care Med. 2016;17(11):571-4. doi: 10.1016/j. mpaic.2016.08.006. 